\title{
The comprehensive anatomical spinal osteotomy and anterior column realignment classification
}

\author{
Presented at the 2018 AANS/CNS Joint Section on Disorders of the Spine and Peripheral Nerves \\ Juan S. Uribe, MD, ${ }^{1}$ Frank Schwab, MD, ${ }^{2}$ Gregory M. Mundis Jr., MD, ${ }^{3}$ David S. Xu, MD, ${ }^{1}$ \\ Jacob Januszewski, DO, ${ }^{4}$ Adam S. Kanter, MD, ${ }^{5}$ David O. Okonkwo, MD, PhD, ${ }^{5}$ \\ Serena S. Hu, MD, ${ }^{6}$ Deviren Vedat, MD, ${ }^{7}$ Robert Eastlack, MD, ${ }^{3}$ Pedro Berjano, MD, PhD, ${ }^{8}$ and \\ Praveen V. Mummaneni, MD ${ }^{9}$
}

\begin{abstract}
'Department of Neurological Surgery, Barrow Neurological Institute, St. Joseph's Hospital and Medical Center, Phoenix, Arizona; 2Department of Orthopedic Surgery, Hospital for Special Surgery, New York, New York; ${ }^{3}$ San Diego Spine Foundation, La Jolla, California; ${ }^{\circ}$ Orlando Neurosurgery, Orlando, Florida; ${ }^{5}$ Department of Neurological Surgery, University of Pittsburgh Medical Center, Pittsburgh, Pennsylvania; ${ }^{6}$ Department of Orthopaedic Surgery, Stanford School of Medicine, Stanford, California; Departments of ${ }^{7}$ Orthopaedic Surgery and ${ }^{9}$ Neurological Surgery, University of California, San Francisco, California; and ${ }^{8}$ RCCS Istituto Ortopedico Galeazzi, Milan, Italy
\end{abstract}

OBJECTIVE Spinal osteotomies and anterior column realignment (ACR) are procedures that allow preservation or restoration of spine lordosis. Variations of these techniques enable different degrees of segmental, regional, and global sagittal realignment. The authors propose a comprehensive anatomical classification system for ACR and its variants based on the level of technical complexity and invasiveness. This serves as a common language and platform to standardize clinical and radiographic outcomes for the utilization of ACR.

METHODS The proposed classification is based on 6 anatomical grades of ACR, including anterior longitudinal ligament (ALL) release, with varying degrees of posterior column release or osteotomies. Additionally, a surgical approach (anterior, lateral, or posterior) was added. Reliability of the classification was evaluated by an analysis of 16 clinical cases, rated twice by 14 different spine surgeons, and calculation of Fleiss kappa coefficients.

RESULTS The 6 grades of ACR are as follows: grade A, ALL release with hyperlordotic cage, intact posterior elements; grade 1 (ACR + Schwab grade 1), additional resection of the inferior facet and joint capsule; grade 2 (ACR + Schwab grade 2), additional resection of both superior and inferior facets, interspinous ligament, ligamentum flavum, lamina, and spinous process; grade 3 (ACR + Schwab grade 3), additional adjacent-level 3-column osteotomy including pedicle subtraction osteotomy; grade 4 (ACR + Schwab grade 4), 2-level distal 3-column osteotomy including pedicle subtraction osteotomy and disc space resection; and grade 5 (ACR + Schwab grade 5), complete or partial removal of a vertebral body and both adjacent discs with or without posterior element resection. Intraobserver and interobserver reliability were $97 \%$ and $98 \%$, respectively, across the 14 -reviewer cohort.

CONCLUSIONS The proposed anatomical realignment classification provides a consistent description of the various posterior and anterior column release/osteotomies. This reliability study confirmed that the classification is consistent and reproducible across a diverse group of spine surgeons.

https://thejns.org/doi/abs/10.3171/2018.4.SPINE171206

KEYWORDS osteotomy; spine deformity; minimally invasive surgery; spine surgery; scoliosis; XLIF; LIF

ABBREVIATIONS ACR = anterior column realignment; $A L L=$ anterior longitudinal ligament; FEA = finite element analysis; $L$ IF = lumbar interbody fusion; LL = lumbar lordosis; MIS = minimally invasive surgery; $\mathrm{PCO}=$ posterior column osteotomy; $\mathrm{PI}=$ pelvic incidence; $\mathrm{SVA}=$ sagittal vertical axis.

SUBMITTED November 2, 2017. ACCEPTED April 3, 2018.

INCLUDE WHEN CITING Published online August 24, 2018; DOI: 10.3171/2018.4.SPINE171206. 
$\mathrm{S}$ AGITTAL malalignment and spinopelvic disharmony contribute significantly to pain and disability in patients with spinal deformities caused by scoliosis, degeneration, and iatrogenic flat-back syndrome. ${ }^{13,28}$ In addition to decompression, instrumentation, and fusion, realignment of the spine has gradually become recognized as an indispensable part of surgical intervention for patients with spinal deformities. The goals of surgery to achieve harmonious spinal alignment are correction of sagittal vertical axis (SVA) $<5 \mathrm{~cm}$, pelvic tilt $<25^{\circ}$, and lumbar lordosis (LL) within $10^{\circ}$ of the pelvic incidence (PI). 5,12,13,15,18,28,29 Traditionally, varying posterior shortening osteotomies were performed to release and reconstruct the spine to achieve appropriate sagittal alignment and spinopelvic harmony. Schwab et al. recently classified osteotomies from the posterior approach. ${ }^{27}$ The classification is anatomically based with graduated complexity that ranges from simple inferior facet resection to those including pedicle subtraction osteotomy and vertebral column resection at 1 or more levels.

Minimally invasive surgery (MIS) via anterolateral lumbar interbody fusion (LIF) has gained significant popularity in the past decade. Initially used for degenerative spinal diseases with the goal of indirect decompression and interbody fusion, the technique has since been added to the spine surgeon's armamentarium to treat adult spinal deformity. The anterior column realignment (ACR) procedure is an extension of anterolateral LIF that incorporates division of the anterior longitudinal ligament (ALL), allowing greater manipulation of the anterior and middle columns across the disc space, which can be further extended into the vertebral body through a partial or complete vertebrectomy. ${ }^{11,38}$ When combined with a posterior release, ACR allows manipulation of all 3 columns of the spine. ${ }^{32,33,39}$ As a result, ACR has enabled minimally invasive strategies to be performed to correct spinal deformities that previously were only treatable through open posterior-based surgeries reliant on osteotomies. ${ }^{1,26}$

Whether to facilitate communication regarding surgical planning, clinical research, or medicofinancial coding, a comprehensive anatomical realignment classification of ACR/osteotomy is needed. In this study, we propose a classification system that provides surgeons with a reference to achieve desired lordosis with varying degrees of anterior column release and osteotomies of the spinal column. This reference is a supplement to the Schwab spinal osteotomy classification and is intended to be anatomically based and comprehensive. The goal of this classification system is to lay the foundation for a common surgical anatomical nomenclature to facilitate communication and research in adult spinal deformity.

\section{Methods}

\section{Supplemental ACR Classification}

We divided the possible combinations of ACR with posterior column osteotomies (PCOs) into 6 anatomical grades of anterior column realignment (Fig. 1), each with a concurrent form of PCO according to the well-established Schwab osteotomy classification. Increasing grades of ACR denote a greater extent of posterior column resec- tion. Likewise, an increasing grade reflects more destabilization and potential for segmental lordosis correction (Fig. 1). Furthermore, surgical approach modifiers are added to describe anterior only, posterior, or combined approaches.

\section{Classification Reliability}

To evaluate the clarity and reliability of the proposed classification system, a single-center database was retrospectively analyzed to create an ACR case series for evaluation. This study was conducted with institutional review board approval for waiver of patient informed consent. Identified cases were chosen to represent a wide range of ACR grades. Preoperative and postoperative sagittal and coronal standing scoliosis radiographs were collected to create illustrative surgical cases. These cases were then integrated into Power Point slides and mixed in random order with a brief operative note following each clinical scenario. A group of 14 orthopedic and neurological surgeons trained in complex spine surgery across multiple institutions then assigned the cases an ACR grade according to the proposed classification system in a blinded fashion to assess interrater reliability. Approximately 2 weeks after the first grading session, the process was repeated with the same cases in a different order to assess intraobserver reliability.

Interobserver and intraobserver reliability were then measured by calculating weighted Fleiss kappa values using IBM SPSS (version 20.0, IBM Corp.). Kappa values of 0.00 to 0.20 were considered slight agreement, 0.21 to 0.40 fair agreement, 0.41 to 0.60 moderate agreement, 0.61 to 0.80 substantial agreement, and 0.81 to 1.00 almost perfect agreement. ${ }^{19,27}$

\section{Review of the Literature}

To evaluate established evidence on the usage and anatomical consequences of ACR with or without PCOs, a systematic review of the literature was performed. We reviewed PubMed and MEDLINE for abstracts and studies examining the ACR technique and its clinical experience since September 2017 through a search for terms "anterior column realignment/release/resection." Two reviewers (J.S.U. and D.S.X.) screened identified studies by their title and abstracts for inclusion in the analysis. If it could not be determined whether an article should be included on the first pass, the entire article was reviewed for inclusion. All selected articles were then assessed for data related to segmental lordosis change, osteotomy type, and cage type measurements. Studies with incomplete data were excluded, and all collected information was summarized for additional analysis.

\section{Results}

\section{Literature Review}

Thirteen studies on ACR were identified, of which 9 included all necessary variables for analysis (Table 1). Data relevant to each specific ACR classification grade are summarized with the relevant ACR grade described below. 


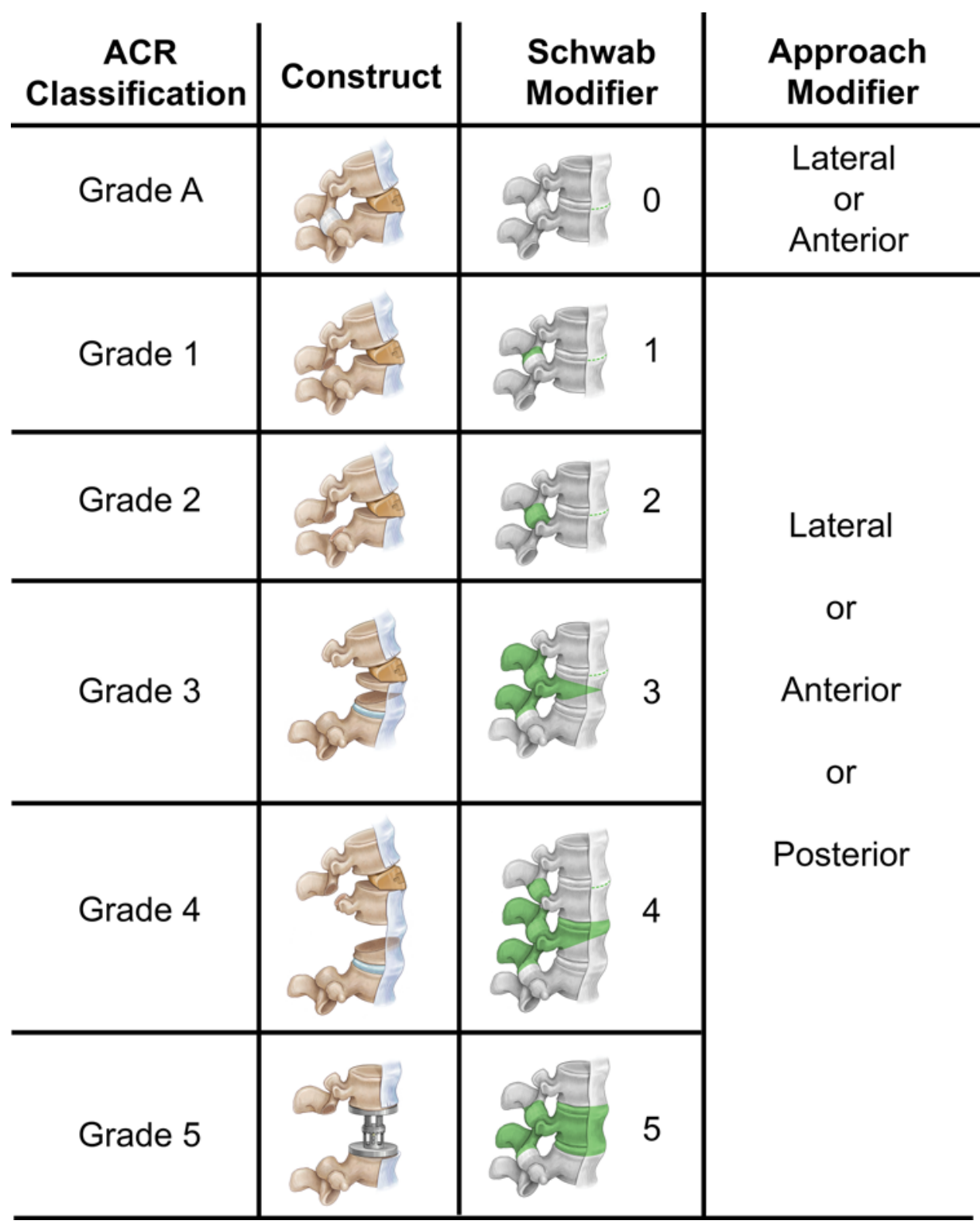

FIG. 1. ACR classification overview. A diagram of the proposed ACR classification with illustrations of each grade's construct, the bony Schwab modifier that defines each grade, and the available approach modifiers. Artwork used with permission from Barrow Neurological Institute.

\section{Description of Classification and Literature Evidence}

Figure 1 provides an overview of the ACR classification grading system. A total of 6 grades exist, ranging from A to 5. Each grade is determined by a Schwab modifier that denotes how much posterior column destabilization is applied to facilitate additional gains in segmental lordosis, as well as an approach modifier, which denotes whether the ALL was released from an anterior, lateral, or posterior approach.

\section{Grade A ACR: ALL Release With Hyperlordotic Cage and Intact Posterior Elements}

Description

A grade A ACR (Fig. 2) involves releasing the ALL without performing any shortening osteotomies posteriorly. The approach is lateral or anterior, and a $20^{\circ}$ or $30^{\circ}$ hyperlordotic cage is used depending on the amount of segmental lordosis restoration desired and the accessibility of the disc space. Approximately $7.8^{\circ}$ of segmental lordosis, with a range of $1^{\circ}-14^{\circ}$, can be gained with a $30^{\circ}$ cage.

\section{Published Techniques Associated With Grade A ACR}

Several publications described ACR without posterior osteotomies and all reported similar degrees of segmental lordosis restoration depending on the angle of the interbody. In the beginning of ACR utilization during 2012, Deukmedjian et al. and Uribe et al. showed a change of $7.5^{\circ}$ to $11^{\circ}$ and $10.6^{\circ}$ to $13.1^{\circ}$ in segmental lordosis correction, 
Uribe et al.

TABLE 1. Summary of lateral ACR literature

\begin{tabular}{|c|c|c|c|c|c|}
\hline $\begin{array}{l}\text { ACR } \\
\text { Grade }\end{array}$ & Authors \& Year & Type of Study & Posterior Osteotomy & Implant Lordosis & $\begin{array}{c}\text { Segmental Lordosis } \\
\text { Change (mean or range) }\end{array}$ \\
\hline \multirow{8}{*}{ A } & Uribe et al., $2012^{38}$ & Cadaveric study & None & $20^{\circ}$ & $9.1-9.5^{\circ}$ \\
\hline & Melikian et al., 2016 & Cadaveric study & None & $20^{\circ}$ & $12^{\circ}$ \\
\hline & Uribe et al., 2015 & FEA & None & $20^{\circ}$ & $14.5-19.5^{\circ}$ \\
\hline & Demirkiran et al., 2016 & Retrospective case series & None & $20^{\circ}$ & $8.7^{\circ}$ \\
\hline & Manwaring et al., 2014 & Retrospective case series & None & $20^{\circ}$ & $12^{\circ}$ \\
\hline & Uribe et al., $2012^{38}$ & Cadaveric study & None & $30^{\circ}$ & $10.6-13.1^{\circ}$ \\
\hline & Uribe et al., 2015 & FEA & None & $30^{\circ}$ & $19.5-22.5^{\circ}$ \\
\hline & Deukmedjian et al., $2012^{11}$ & Retrospective case series & None & $30^{\circ}$ & $7.5-11^{\circ}$ \\
\hline \multirow{4}{*}{1} & Uribe et al., 2015 & FEA & Inferior facetectomy & $20^{\circ}$ & $21-23^{\circ}$ \\
\hline & Uribe et al., 2015 & FEA & Inferior facetectomy & $30^{\circ}$ & $22.5-26^{\circ}$ \\
\hline & Demirkiran et al., 2016 & Retrospective case series & Inferior facetectomy & $30^{\circ}$ & $14.2^{\circ}$ \\
\hline & Turner et al., 2015 & $\begin{array}{l}\text { Retrospective multicenter } \\
\text { case series }\end{array}$ & $\begin{array}{l}\text { Inferior facetectomy or complete } \\
\text { facetectomy }\end{array}$ & 20 or $30^{\circ}$ & $15.4-18.2^{\circ}$ \\
\hline \multirow{5}{*}{2} & Uribe et al., 2015 & FEA & Complete facetectomy & $20^{\circ}$ & $24-25^{\circ}$ \\
\hline & Akbarnia et al., 2014 & Retrospective case series & Complete facetectomy & $20^{\circ}$ & $22-24^{\circ}$ \\
\hline & Uribe et al., 2015 & FEA & Complete facetectomy & $30^{\circ}$ & $32-33^{\circ}$ \\
\hline & Berjano et al., 2015 & Retrospective case series & Complete facetectomy & $30^{\circ}$ & $24-35^{\circ}$ \\
\hline & Akbarnia et al., 2014 & Retrospective case series & Complete facetectomy & $30^{\circ}$ & $8-47^{\circ}$ \\
\hline $3 \& 4$ & Uribe \& Mundis & Personal cases & Pedicle subtraction osteotomy & $30^{\circ}$ & $46^{\circ}$ \\
\hline 5 & Mundis & Personal case & Vertebral body corpectomy & Expandable $0^{\circ}$ cage & $48^{\circ}$ \\
\hline
\end{tabular}

respectively, for a $30^{\circ}$ cage..$^{10,11,38}$ Uribe et al. also showed $9.1^{\circ}-9.5^{\circ}$ of segmental lordosis restoration for $20^{\circ}$ cages $^{38}$ Manwaring et al. and Melikian et al. both showed an average of $12^{\circ}$ of correction in segmental lordosis for grade A ACR with $30^{\circ}$ hyperlordotic cages. ${ }^{20,21}$ Later, Uribe et al. performed a finite element analysis (FEA) with $20^{\circ}$ and $30^{\circ}$ cages, demonstrating a range of $14.5^{\circ}-19.5^{\circ}$ of segmental lordosis correction for $20^{\circ}$ cages and $19.5^{\circ}-22.5^{\circ}$ of correction for $30^{\circ}$ cages. $^{37}$

\section{Grade 1 ACR: ALL Release With Hyperlordotic Cage and Inferior Facetectomy (Schwab grade 1) \\ Description}

A grade 1 ACR comprises an ALL release with application of an intervertebral cage combined with resection of the inferior facet and joint capsule at a given spinal level with or without interspinous ligament resection (Fig. 3). Approximately $13.1^{\circ}$ of segmental lordosis (range $3^{\circ}-26^{\circ}$ ) can be gained with grade 1 and a $30^{\circ}$ cage.

\section{Published Techniques Associated With Grade 1 ACR}

Demirkiran et al. described ACRs combined with adjacent partial facetectomies with either $20^{\circ}$ or $30^{\circ}$ hyperlordotic cages. Changes in segmental lordosis restoration averaged $8.7^{\circ}$ for $20^{\circ}$ cages and $14.2^{\circ}$ for $30^{\circ}$ cages..$^{9}$ Turner et al. described ACRs with either partial or complete facetectomies; however, they did not specify the cage size. They reported a change in segmental lordosis restoration ranging from $15.4^{\circ}$ to $18.2^{\circ} .35$ The FEA of Uribe et al. showed a correction of $21^{\circ}-23^{\circ}$ in segmental lordosis for $20^{\circ}$ cages and $22.5^{\circ}-26^{\circ}$ of segmental lordosis correction for $30^{\circ}$ cages. $^{37}$

\section{Grade 2 ACR: ALL Release With Hyperlordotic Cage and PCO (Schwab grade 2)}

Description

A grade 2 ACR involves ALL release with the addition of a hyperlordotic cage combined with both superior and inferior facet resection at a given spinal segment. Additionally, the interspinous ligament, ligamentum flavum, and other posterior elements of the vertebra, including the lamina and the spinous process, may also be resected (Fig. 4).

\section{Published Techniques Associated With Grade 2 ACR}

Berjano et al. described ACR with $30^{\circ}$ hyperlordotic cages and Schwab grade 2 PCOs with subsequent segmental correction ranging between $24^{\circ}$ and $35^{\circ} .6$ Akbarnia et al. described $22^{\circ}-24^{\circ}$ of correction for $20^{\circ}$ cages and $8^{\circ}-$ $47^{\circ}$ of correction for $30^{\circ}$ cages..$^{1}$ Uribe et al.'s FEA analysis showed $24^{\circ}-25^{\circ}$ changes in segmental lordosis for $20^{\circ}$ cages and $32^{\circ}-33^{\circ}$ changes for $30^{\circ}$ cages with PCO. ${ }^{37}$ The average segmental lordosis gained was $22.6^{\circ}$ for Grade 2 ACRs with a $30^{\circ}$ hyperlordotic cage (range $8^{\circ}-47^{\circ}$ ).

\section{Grade 3 and 4 ACRS: ALL Release With Hyperlordotic Cage and 3-Column Osteotomy (Schwab grades 3 and 4)} Description

Grade 3 and 4 ACRs incorporate an adjacent 3-column osteotomy, including pedicle subtraction osteotomies and wedge vertebral body resections. For grade $3 \mathrm{ACR}$, the 3-column osteotomy occurs through the adjacent vertebral body alone (Fig. 5). In a grade 4 ACR, the 3-column osteotomy is placed 2 vertebrae distal to the ACR implant, and the 

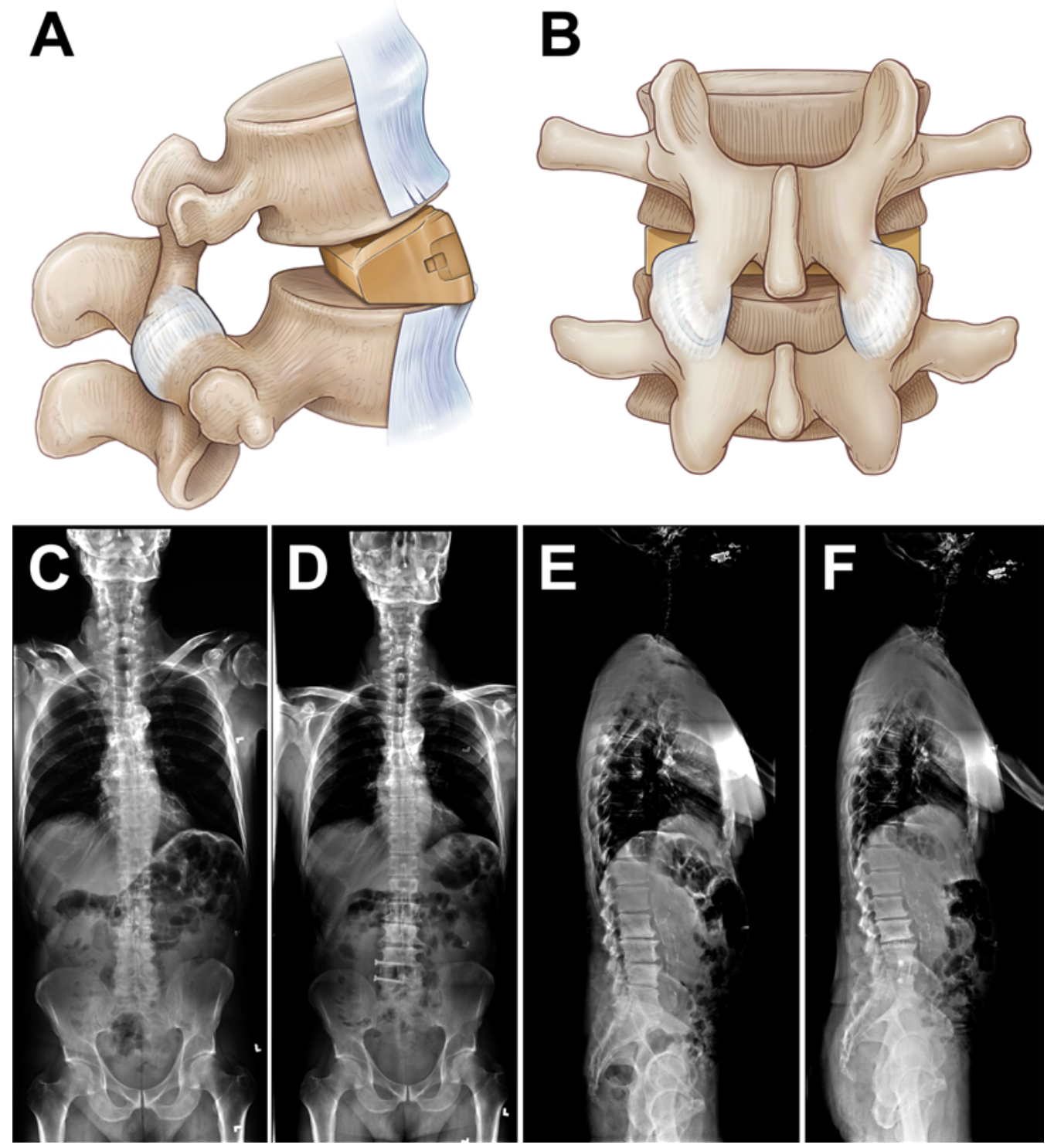

FIG. 2. Grade A ACR. ALL release with hyperlordotic cage and intact posterior elements. Lateral $(\mathbf{A})$ and posterior (B) views of the construct, showing that no posterior bony work has been done. Anteroposterior (C and $\mathbf{D})$ and lateral (E and F) standing radiographs obtained in a patient who underwent a stand-alone lateral Grade A ACR at L4-5. Panels A and B used with permission from Barrow Neurological Institute.

cuts run through the distal adjacent disc space for additional gains in segmental lordosis (Fig. 5). There are no published data regarding grade 3 and 4 ACR, but on a geometrical basis, we believe that if a correction of more than $30^{\circ}$ is necessary, a grade 3 ACR or higher should be considered.

\section{Grade 5 ACR: Vertebrectomy With ALL Release Description}

Grade 5 ACR is the complete or partial removal of a vertebral body and both adjacent discs through a lateral, anterior, or posterior approach (Fig. 6). If the ACR occurs in the thoracic spine, rib head resection is also required. A Grade 5 ACR can involve the vertebral body and disc resection alone, or incorporate different amounts of posterior column resection.

\section{Published Techniques Associated With Grade 3-5 ACR}

Unfortunately, because of the scarcity of severe deformity cases requiring these aggressive surgical maneuvers, we could use only isolated case reports and observational studies from our clinical experience as a reference. These limited examples demonstrate that a change in segmental lordosis with gains greater than $40^{\circ}$ is achievable through grade 3-5 ACRs. There are not enough published data to quantify a definitive range of radiographic outcomes that are achievable.

\section{Interobserver and Intraobserver Reliability}

Data from a total of 16 patients were collected and composed into surgical cases for rating reliability analysis. Four cases were classified as grade A, 4 cases as 
Uribe et al.
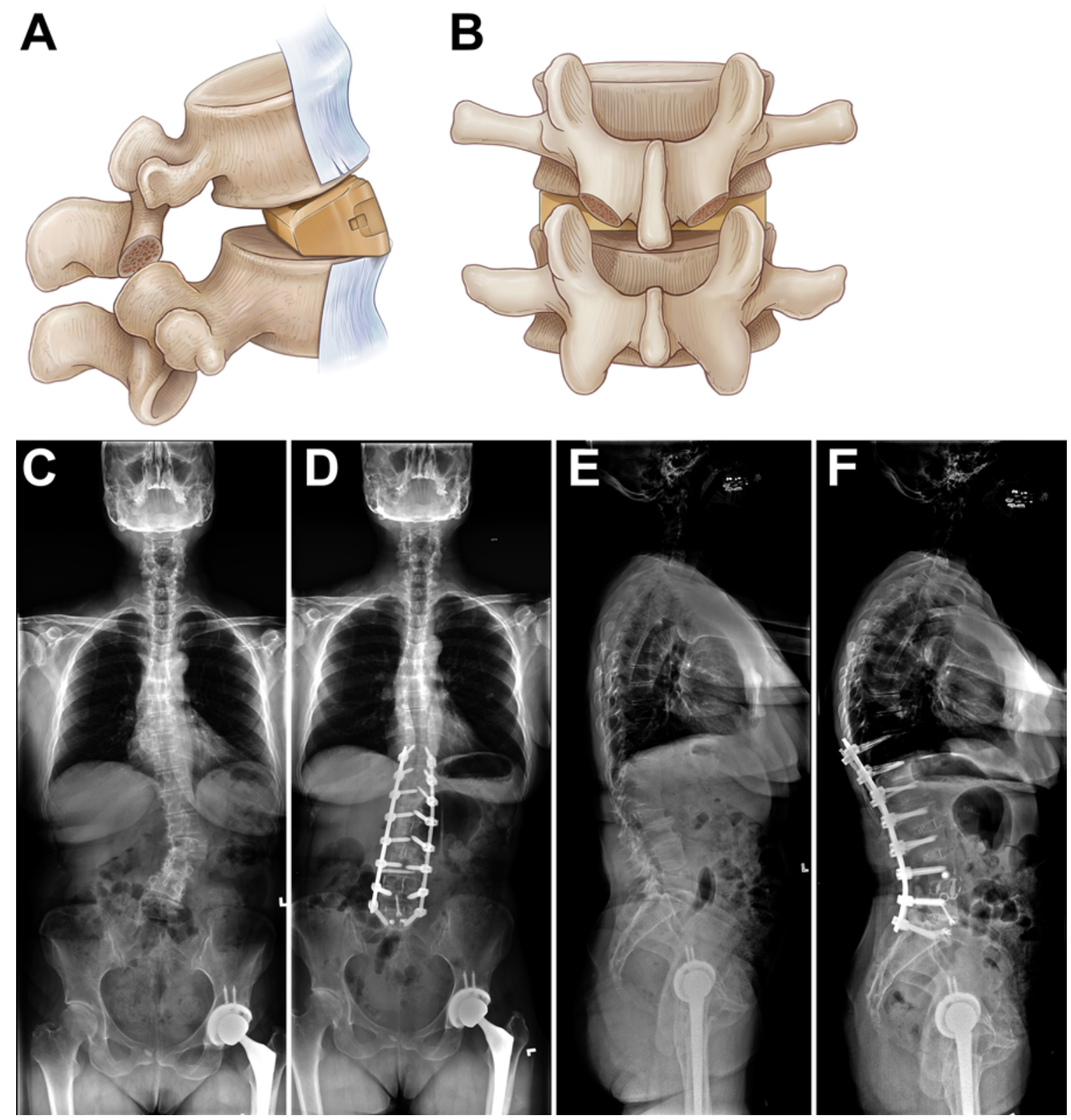

FIG. 3. Grade 1 ACR: ALL release with hyperlordotic cage and inferior facetectomy. Lateral $(\mathbf{A})$ and posterior $(\mathbf{B})$ illustrations of the construct showing release of the ALL and complete bilateral inferior facetectomies. Anteroposterior $(C$ and $D)$ and lateral $(E$ and F) standing radiographs demonstrating a T11-S1 revision construct with an anterior grade 1 ACR at L5-S1 and a grade A ACR at L4-5. Panels A and B used with permission from Barrow Neurological Institute.

grade 1,4 cases as grade 2, 2 cases as grade 3 , and 2 cases as grade 4 .

The interobserver reliability of the ACR grade (without the modifiers) was rated as "almost perfect" with a corresponding weighted Fleiss kappa coefficient average of 0.98 and $95 \%$ CI of 0.96-0.99. Within literature standards, kappa values greater than 0.75 are considered to have a high degree of agreement beyond chance. ${ }^{7}$ Values below 0.40 have a low degree of agreement and values between 0.40 and 0.75 represent a fair to good level of agreement beyond chance alone. When both modifiers are included, weighted kappa decreased slightly to 0.96 or $96 \%$ agreement; however, this is still considered "near perfect" reliability.
When the order of the 16 cases was re-randomized and reviewed again by our 14 surgeons 2 weeks later, the intraobserver weighted Fleiss kappa coefficient was 0.98 with a 95\% CI of 0.97-0.99, suggesting excellent intraobserver consistency.

\section{Discussion}

Compared with open surgical techniques, MIS for degenerative spinal conditions has demonstrated decreased blood loss, length of stay, and risk of infection, while also preserving paraspinal musculature. ${ }^{23,40}$ However, early application of MIS for the treatment of spinal deformi- 

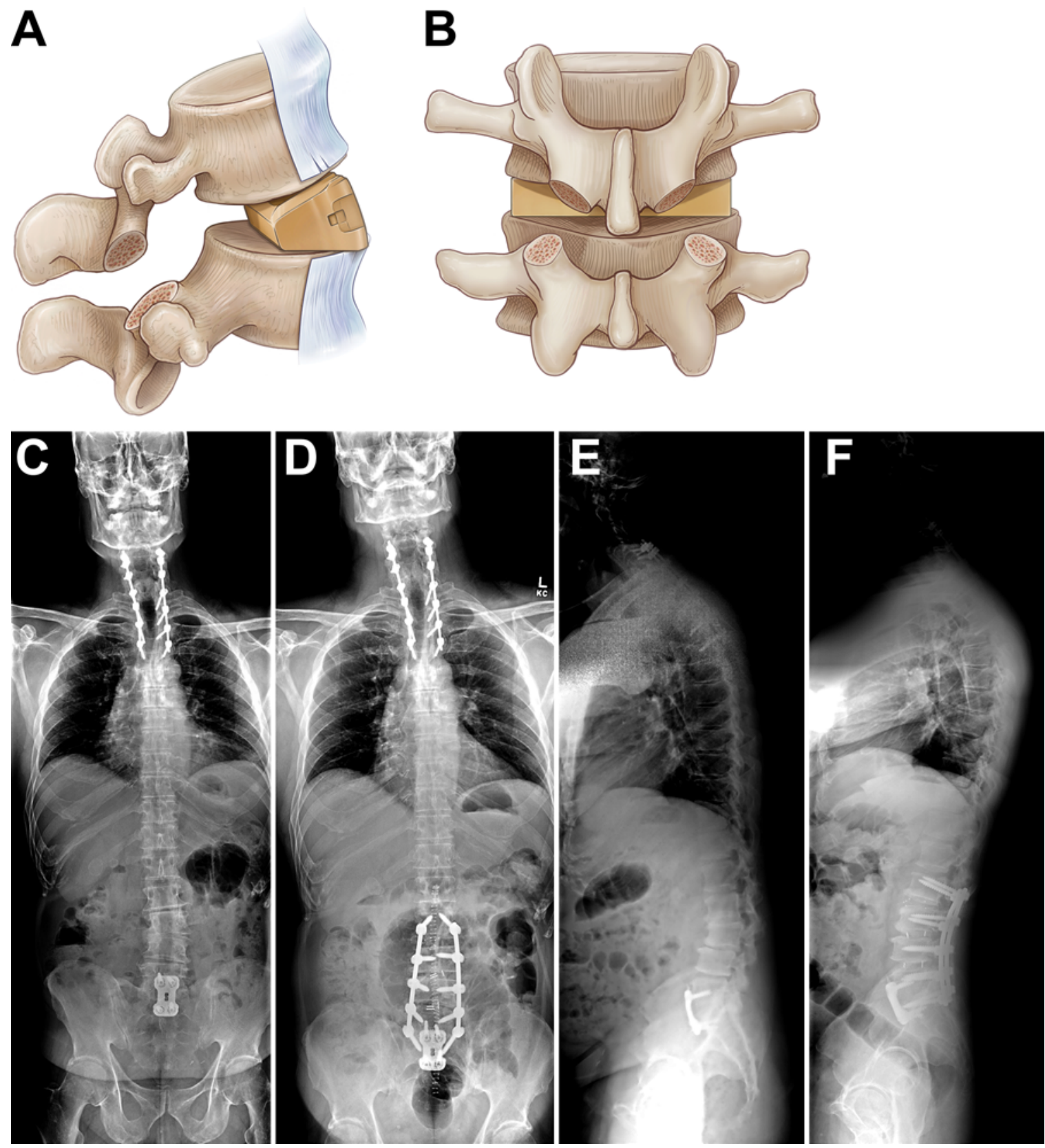

FIG. 4. Grade 2 ACR: ALL release with hyperlordotic cage and complete facetectomies. Lateral (A) and posterior (B) illustrations of the construct showing release of the ALL and complete bilateral superior and inferior facetectomies. Anteroposterior (C and D) and lateral ( $E$ and $F$ ) standing radiographs demonstrating a posterior grade 2 ACR at L2-3 to correct a focal kyphotic deformity. Panels A and B used with permission from Barrow Neurological Institute.

ties was limited due to inadequate restoration of sagittal spinopelvic imbalance and PI-LL mismatch. ${ }^{8,14}$ Initial attempts to apply MIS strategies only targeted patients with mild spinal deformities, including low pelvic tilt, low PI, or purely coronal curve corrections. ${ }^{2,17}$ Since the introduction of ACR, multiple studies have demonstrated an expansion in the ability of MIS techniques to successfully treat moderate to severe adult deformities with excellent SVA correction $( \pm 5 \mathrm{~mm} \mathrm{SVA})$ and PI-LL correction $\left( \pm 10^{\circ}\right)$, particularly when hyperlordotic cages are used. ${ }^{3,24,34,36}$ Further examination of segmental lordosis restoration showed that a combination of ACR and varying degrees of PCOs can achieve greater correction of segmental lordosis, regional lordosis, and restoration of global sagittal balance. , $26,37^{2}$

Over the past 5 years, an increasing number of publications have described the role of ACR in adult deformity correction and its role in MIS correction of sagittal malalignment. ${ }^{1,911,21,25,38}$ Several studies have looked at the segmental change in lordosis in ACR with or without PCOs. Depending on the extent of adjacent posterior column resection, varying degrees of segmental correction can be achieved with ALL release and hyperlordotic cages. The 
Uribe et al.
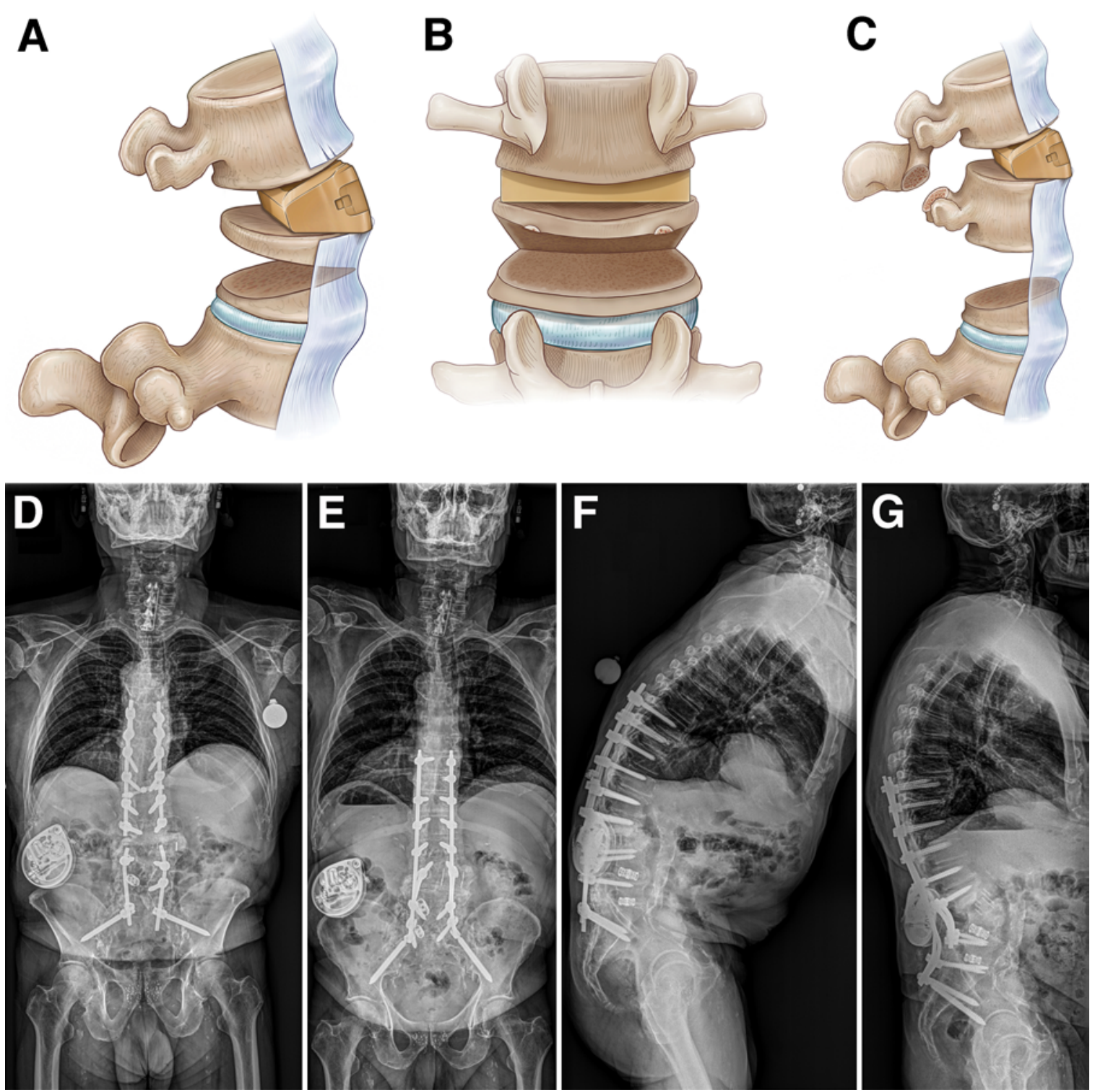

FIG. 5. Grade 3 and 4 ACR: ALL release with hyperlordotic cage and pedicle subtraction osteotomies. A and B: Lateral (A) and posterior (B) illustrations of the construct showing release of the ALL and a posterior pedicle subtraction osteotomy across the inferior vertebral body below the level of the ALL release. C: Additional lordosis can be achieved through a grade 4 ACR where a higher Schwab modifier includes a pedicle subtraction osteotomy through the disc space and vertebral body 2 levels distal to the interbody. D-G: Anteroposterior ( $D$ and $E$ ) lateral ( $F$ and $G$ ) standing radiographs demonstrating a lateral T10-ilium revision construct where a lateral grade 3 ACR was performed at L3-4 to correct a focal kyphotic deformity. Panels A-C used with permission from Barrow Neurological Institute.

greatest effect on the amount of segmental lordosis change is the severity of preoperative segmental kyphosis, the size of the cage used with ALL release $\left(20^{\circ}\right.$ or $\left.30^{\circ}\right)$, and the amount of posterior column resection. However, various forms of confusing and inaccurate osteotomy language have been ineffectively used when describing radiographic outcomes in the literature. Thus, a unified nomenclature is needed to accurately classify ACR and standardize its description in the literature. Without a consistent and anatomically based classification system, the analysis of outcomes and comparison of results through a common language among surgeons treating deformities is not feasible.
The proposed ACR classification is simple, reliable, practical, and easy to adopt. The gradations of ACR are organized in progression of surgical complexity and degree of spinal destabilization and integrate with the wellestablished and reliable Schwab osteotomy classification. ${ }^{27}$ Grades A-2 are "workhorse" techniques, typically applied in flexible or stiff spinal segments. Grades 3-5 are extensions of 3-column osteotomies and are best reserved for fixed/rigid deformities. Increasing degrees of segmental lordosis can be achieved with each increasing grade. The reported incremental segmental lordosis corrections are not, by any means, an exact definitive scale and should 

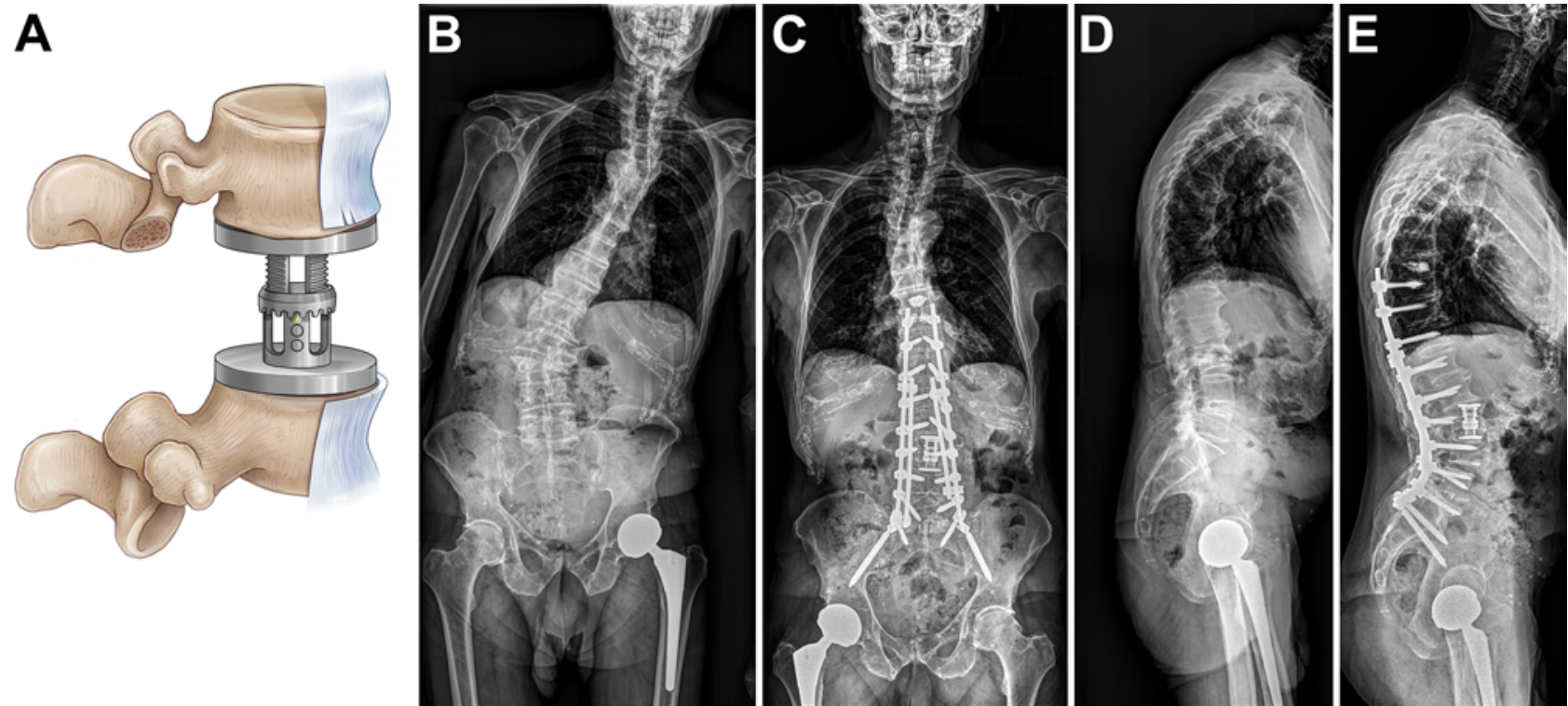

FIG. 6. Grade 5 ACR: ALL release with vertebral body resection. A: Lateral illustration of the construct showing release of the ALL with vertebrectomy of the inferior body. The degree of vertebrectomy can vary from a complete to partial corpectomy in both height and width to accommodate different implant sizes or to preserve bony structures for fixation. B-E: Anterior-posterior (B and C) and lateral (D and E) standing radiographs demonstrating a T10-ilium construct with a lateral grade 5 ACR at L2-4 to correct a focal kyphotic deformity caused by progressive osteomyelitis. The vertebrectomy involved most of the body, but preserved the pedicles for additional fixation points. Panel A used with permission from Barrow Neurological Institute.

only be used as a guide rather than a rule. Variations in degrees of sagittal correction may be impacted by the technical execution of the ACR. For example, the senior author (J.S.U.) typically performs the posterior osteotomies in lateral grade 1 or 2 ACR first in order to maximize the size of interbody placement. However, a smaller interbody cage could be placed first, and then the posterior osteotomies performed second, with in situ rod contouring used to maximize segmental lordosis.

Through lengthening of the anterior column to generate lordosis rather than shortening the posterior column, ACR represents a fundamentally different conceptual paradigm from posterior osteotomies for sagittal realignment. Previously, there have been no formal organizational systems that outline anterior column manipulation techniques in a systematic fashion for surgical planning and communication. Our classification system fills this need and encompasses ACR techniques not only by their anatomical basis, but also by their approach, allowing inclusion of both MIS and open strategies. In turn, ACR can be recognized as more than just an extension of lateral LIF, enabling comprehensive description of different means of manipulating the anterior column such as through anterior LIF $^{16}$ and posterior approaches. ${ }^{31}$ The "approach" modifier, while not important for grades A-2, can become valuable in grades $3-5$, especially in the management of highly complex deformities. Mild variations in technical execution of the various ACR grades can exist, but comparative analysis is still possible through a unified nomenclature.

\section{Generalizability and Limitations}

Any attempt to organize and classify a group of different techniques based on retrospective data comes with an inherent selection bias. The ACR technique is slowly increasing in popularity, but we are currently limited to only 9 studies published since 2012 describing the various ACR grades, each with limited patient numbers and radiographic analysis. Furthermore, although our classification model is validated by "nearly perfect" intra- and interobserver reliability, its utility and likelihood of adaptation by spine surgeons remains unproved.

While the focus of this paper is purely on anatomical classification of osteotomy/release realignment techniques, it is vital to keep in mind the potential morbidity of these procedures, especially at the beginning of the learning curve. The complication rate of the ACR and Schwab grade 3-5 osteotomies has been reported to range from $18 \%$ to $47 \%$ and includes major vascular injury, bowel perforation, and neurological injuries.,22,26,30 These procedures should be performed only by surgeons trained in treating complex deformities and only when indicated and surgically feasible.

\section{Conclusions}

The proposed comprehensive anatomical classification of ACR techniques provides a consistent and dependable description of the various anterior lengthening releases combined with the well-established and reliable posterior Schwab osteotomy classification performed in the field of spine deformity surgery. Results of the reliability study show a near-perfect intraobserver and interobserver reliability, validating this classification system as a simple, consistent, and reproducible tool. Its application in varying scales of deformity correction confirms the classification's practicality. Adaptation and use of this classification sys- 
tem will provide a common platform for spine surgeons to communicate effectively and facilitate further progress in the field of deformity correction.

\section{Acknowledgments}

We thank the Barrow Neurological Institute Neuroscience Publications Office for their assistance with medical illustrations and manuscript preparation.

\section{References}

1. Akbarnia BA, Mundis GM Jr, Moazzaz P, Kabirian N, Bagheri R, Eastlack RK, et al: Anterior column realignment (ACR) for focal kyphotic spinal deformity using a lateral transpsoas approach and ALL release. J Spinal Disord Tech 27:29-39, 2014

2. Anand N, Cohen JE, Cohen RB, Khandehroo B, Kahwaty S, Baron E: Comparison of a newer versus older protocol for circumferential minimally invasive surgical (CMIS) correction of adult spinal deformity (ASD) - evolution over a 10year experience. Spine Deform 5:213-223, 2017

3. Anand N, Sardar ZM, Simmonds A, Khandehroo B, Kahwaty S, Baron EM: Thirty-day reoperation and readmission rates after correction of adult spinal deformity via circumferential minimally invasive surgery-analysis of a 7-year experience. Spine Deform 4:78-83, 2016

4. Auerbach JD, Lenke LG, Bridwell KH, Sehn JK, Milby AH, Bumpass D, et al: Major complications and comparison between 3-column osteotomy techniques in 105 consecutive spinal deformity procedures. Spine (Phila Pa 1976) 37:1198-1210, 2012

5. Banno T, Togawa D, Arima H, Hasegawa T, Yamato Y, Kobayashi S, et al: The cohort study for the determination of reference values for spinopelvic parameters (T1 pelvic angle and global tilt) in elderly volunteers. Eur Spine J 25:36873693, 2016

6. Berjano P, Cecchinato R, Sinigaglia A, Damilano M, Ismael MF, Martini C, et al: Anterior column realignment from a lateral approach for the treatment of severe sagittal imbalance: a retrospective radiographic study. Eur Spine J 24 (Suppl 3):433-438, 2015

7. Cicchetti DV: Guidelines, criteria, and rules of thumb for evaluating normed and standardized assessment instrument in psychology. Psychol Assess 6:284-290, 1994

8. Costanzo G, Zoccali C, Maykowski P, Walter CM, Skoch J, Baaj AA: The role of minimally invasive lateral lumbar interbody fusion in sagittal balance correction and spinal deformity. Eur Spine J 23 (Suppl 6):699-704, 2014

9. Demirkiran G, Theologis AA, Pekmezci M, Ames C, Deviren V: Adult spinal deformity correction with multi-level anterior column releases: description of a new surgical technique and literature review. Clin Spine Surg 29:141-149, 2016

10. Deukmedjian AR, Dakwar E, Ahmadian A, Smith DA, Uribe JS: Early outcomes of minimally invasive anterior longitudinal ligament release for correction of sagittal imbalance in patients with adult spinal deformity. Sci World J 2012:789698, 2012

11. Deukmedjian AR, Le TV, Baaj AA, Dakwar E, Smith DA, Uribe JS: Anterior longitudinal ligament release using the minimally invasive lateral retroperitoneal transpsoas approach: a cadaveric feasibility study and report of 4 clinical cases. J Neurosurg Spine 17:530-539, 2012

12. Diebo BG, Oren JH, Challier V, Lafage R, Ferrero E, Liu S, et al: Global sagittal axis: a step toward full-body assessment of sagittal plane deformity in the human body. J Neurosurg Spine 25:494-499, 2016

13. Glassman SD, Bridwell K, Dimar JR, Horton W, Berven S,
Schwab F: The impact of positive sagittal balance in adult spinal deformity. Spine (Phila Pa 1976) 30:2024-2029, 2005

14. Hamilton DK, Kanter AS, Bolinger BD, Mundis GM Jr, Nguyen S, Mummaneni PV, et al: Reoperation rates in minimally invasive, hybrid and open surgical treatment for adult spinal deformity with minimum 2-year follow-up. Eur Spine J 25:2605-2611, 2016

15. Hasegawa K, Okamoto M, Hatsushikano S, Shimoda H, Ono $\mathrm{M}$, Watanabe K: Normative values of spino-pelvic sagittal alignment, balance, age, and health-related quality of life in a cohort of healthy adult subjects. Eur Spine J 25:3675-3686, 2016

16. Hosseini P Jr, Mundis GM Jr, Eastlack RK, Bagheri R, Vargas E, Tran S, et al: Preliminary results of anterior lumbar interbody fusion, anterior column realignment for the treatment of sagittal malalignment. Neurosurg Focus 43(6):E6, 2017

17. Kanter AS, Tempel ZJ, Ozpinar A, Okonkwo DO: A review of minimally invasive procedures for the treatment of adult spinal deformity. Spine (Phila Pa 1976) 41 (Suppl 8):S59S65, 2016

18. Lafage R, Schwab F, Challier V, Henry JK, Gum J, Smith J, et al: Defining spino-pelvic alignment thresholds: should operative goals in adult spinal deformity surgery account for age? Spine (Phila Pa 1976) 41:62-68, 2016

19. Landis JR, Koch GG: The measurement of observer agreement for categorical data. Biometrics 33:159-174, 1977

20. Manwaring JC, Bach K, Ahmadian AA, Deukmedjian AR, Smith DA, Uribe JS: Management of sagittal balance in adult spinal deformity with minimally invasive anterolateral lumbar interbody fusion: a preliminary radiographic study. $\mathbf{J}$ Neurosurg Spine 20:515-522, 2014

21. Melikian R, Yoon ST, Kim JY, Park KY, Yoon C, Hutton W: Sagittal plane correction using the lateral transpsoas approach: a biomechanical study on the effect of cage angle and surgical technique on segmental lordosis. Spine (Phila Pa 1976) 41:E1016-E1021, 2016

22. Murray G, Beckman J, Bach K, Smith DA, Dakwar E, Uribe JS: Complications and neurological deficits following minimally invasive anterior column release for adult spinal deformity: a retrospective study. Eur Spine J 24 (Suppl 3):397-404, 2015

23. O’Toole JE, Eichholz KM, Fessler RG: Surgical site infection rates after minimally invasive spinal surgery. J Neurosurg Spine 11:471-476, 2009

24. Phan K, Rao PJ, Scherman DB, Dandie G, Mobbs RJ: Lateral lumbar interbody fusion for sagittal balance correction and spinal deformity. J Clin Neurosci 22:1714-1721, 2015

25. Pimenta L, Fortti F, Oliveira L, Marchi L, Jensen R, Coutinho E, et al: Anterior column realignment following lateral interbody fusion for sagittal deformity correction. Eur J Orthop Surg Traumatol 25 (Suppl 1):S29-S33, 2015

26. Saigal R, Mundis GM Jr, Eastlack R, Uribe JS, Phillips FM, Akbarnia BA: Anterior column realignment (ACR) in adult sagittal deformity correction: technique and review of the literature. Spine (Phila Pa 1976) 41 (Suppl 8):S66-S73, 2016

27. Schwab F, Blondel B, Chay E, Demakakos J, Lenke L, Tropiano $\mathrm{P}$, et al: The comprehensive anatomical spinal osteotomy classification. Neurosurgery 74:112-120, 2014

28. Schwab F, Lafage V, Patel A, Farcy JP: Sagittal plane considerations and the pelvis in the adult patient. Spine (Phila Pa 1976) 34:1828-1833, 2009

29. Schwab F, Patel A, Ungar B, Farcy JP, Lafage V: Adult spinal deformity-postoperative standing imbalance: how much can you tolerate? An overview of key parameters in assessing alignment and planning corrective surgery. Spine (Phila Pa 1976) 35:2224-2231, 2010

30. Smith JS, Shaffrey CI, Klineberg E, Lafage V, Schwab F, 
Lafage R, et al: Complication rates associated with 3-column osteotomy in 82 adult spinal deformity patients: retrospective review of a prospectively collected multicenter consecutive series with 2-year follow-up. J Neurosurg Spine 27:444457, 2017

31. Sweet FA, Sweet A: Transforaminal anterior release for the treatment of fixed sagittal imbalance and segmental kyphosis, minimum 2-year follow-up study. Spine Deform 3:502-511, 2015

32. Tan LA, Kasliwal MK, O’Toole JE: Minimally invasive combined direct lateral and posterior transpedicular approach for $360^{\circ}$ resection of a lumbar aneurysmal bone cyst with spinal stabilization. Spine J 15:e37-e38, 2015

33. Tan T, Chu J, Thien C, Wang YY: Minimally invasive direct lateral corpectomy of the thoracolumbar spine for metastatic spinal cord compression. J Neurol Surg A Cent Eur Neurosurg 78:358-367, 2017

34. Tay KS, Bassi A, Yeo W, Yue WM: Associated lumbar scoliosis does not affect outcomes in patients undergoing focal minimally invasive surgery-transforaminal lumbar interbody fusion (MISTLIF) for neurogenic symptoms - a minimum 2-year follow-up study. Spine J 17:34-43, 2017

35. Turner JD, Akbarnia BA, Eastlack RK, Bagheri R, Nguyen S, Pimenta L, et al: Radiographic outcomes of anterior column realignment for adult sagittal plane deformity: a multicenter analysis. Eur Spine J 24 (Suppl 3):427-432, 2015

36. Uribe JS, Beckman J, Mummaneni PV, Okonkwo D, Nunley P, Wang MY, et al: Does MIS surgery allow for shorter constructs in the surgical treatment of adult spinal deformity? Neurosurgery 80:489-497, 2017

37. Uribe JS, Harris JE, Beckman JM, Turner AW, Mundis GM, Akbarnia BA: Finite element analysis of lordosis restoration with anterior longitudinal ligament release and lateral hyperlordotic cage placement. Eur Spine J 24 (Suppl 3):420-426, 2015

38. Uribe JS, Smith DA, Dakwar E, Baaj AA, Mundis GM, Turner AW, et al: Lordosis restoration after anterior longitudinal ligament release and placement of lateral hyperlordotic interbody cages during the minimally invasive lateral transpsoas approach: a radiographic study in cadavers. $\mathbf{J}$ Neurosurg Spine 17:476-485, 2012

39. Uribe JS, Smith WD, Pimenta L, Härtl R, Dakwar E, Modhia $\mathrm{UM}$, et al: Minimally invasive lateral approach for symptomatic thoracic disc herniation: initial multicenter clinical experience. J Neurosurg Spine 16:264-279, 2012

40. Yen CP, Mosley YI, Uribe JS: Role of minimally invasive surgery for adult spinal deformity in preventing complications. Curr Rev Musculoskelet Med 9:309-315, 2016

\section{Disclosures}

Dr. Uribe: consultant for NuVasive and Misonix, and direct stock ownership in NuVasive. Dr. Schwab: consultant for Zimmer Biomet, MSD, K2M, and NuVasive; direct stock ownership in Nemaris Inc.; speaking/teaching arrangements with Zimmer Biomet, MSD, K2M, and NuVasive; support of non-studyrelated clinical or research effort from DePuy, NuVasive, K2M, and Stryker (paid through ISSGF). Dr. Mundis: consultant for NuVasive, K2M, and Allosource; and patent holder with NuVasive and K2M. Dr. Hu: direct stock ownership in and intellectual property with NuVasive. Dr. Eastlack: consultant for NuVasive, Aesculap, Seaspine, Titan, K2M, and Alphatec; direct stock ownership in NuVasive, Seaspine, and Alphatech; ownership in Spine Innovation; patent holder with NuTech, Globus Medical, and Ivuity; and consultant for SI Bone. Dr. Berjano: consultant for NuVasive and Medacta and support of non-study-related clinical or research effort from DePuy Synthes, NuVasive, and K2M. Dr. Mummaneni: consultant for DePuy Spine, Globus, and Stryker; direct stock ownership in Spinicity/ISD; support of non-studyrelated clinical or research effort from ISSG and NREF; royalties from DePuy Spine, and Thieme Publishing, Springer Publishing; and honoraria from AO Spine.

\section{Author Contributions}

Conception and design: Uribe. Acquisition of data: Schwab, Mundis, Januszewski, Hu, Deviren, Eastlack, Berjano, Mummaneni. Analysis and interpretation of data: Uribe, Schwab, Mundis, Januszewski, Kanter, Okonkwo, Hu, Deviren, Eastlack. Drafting the article: Uribe, Xu, Januszewski, Kanter, Okonkwo, Mummaneni. Critically revising the article: Uribe, Schwab, Mundis, Xu, Kanter, Okonkwo, Deviren, Berjano, Mummaneni. Reviewed submitted version of manuscript: Uribe, Xu, Eastlack, Berjano, Mummaneni. Administrative/technical/material support: Xu.

\section{Supplemental Information}

\section{Previous Presentations}

An early version of this study was presented at Spine Summit 2018: 34th Annual Meeting of the Section on Disorders of the Spine and Peripheral Nerves, Orlando, FL, March 17, 2018.

\section{Correspondence}

Juan S. Uribe: Barrow Neurological Institute, St. Joseph's Hospital and Medical Center, Phoenix, AZ. juansuribe@gmail.com. 